\title{
Dietary 20:4n-6 and 22:6n-3 Modulates the Profile of Long- and Very-Long-Chain Fatty Acids, Rhodopsin Content, and Kinetics in Developing Photoreceptor Cells
}

\author{
MIYOUNG SUH, ANTONI A. WIERZBICKI, ERIC L. LIEN, AND M. THOMAS CLANDININ \\ Nutrition and Metabolism Research Group [M.S., A.A.W., M.T.C.], Department of Agricultural, \\ Food, and Nutritional Science [M.S., A.A.W., M.T.C.], and Department of Medicine [M.T.C.], \\ University of Alberta, Edmonton, Alberta, Canada T6G 2P5; and Wyeth-Ayerst Research, \\ Philadelphia, Pennsylvania, U.S.A. [E.L.L.]
}

\begin{abstract}
The objective of this study was to determine whether addition of dietary 20:4n-6 and 22:6n-3 to a conventional infant formula fat blend influences membrane long-chain and very-long-chain fatty acid composition, rhodopsin content, and rhodopsin kinetics in developing rat photoreceptor cells. The dietary fats were formulated based on the fat composition of a conventional infant formula providing an 18:2n-6/18:3n-3 ratio of 7:1 (SMA, Wyeth Nutritionals), which served as the control fat blend. This dietary fat blend was modified to contain 20:4n-6 [arachidonic acid (AA)], 22:6n-3 [docosahexaenoic acid (DHA)], AA + DHA, or an 18:2n-6/18:3n-3 ratio of 4:1 ( $\alpha$-linolenic acid). Dams were fed diets from birth, and rat pups were fed the same diet after weaning. Retinas and rod outer segments were prepared in the dark from pups at 2,3, and 6 wk of age for fatty acid analysis of individual phospholipids, rhodopsin content, and rhodopsin disappearance kinetics after light exposure. Feeding AA + DHA in the diet increased 22:6n-3 levels in phosphatidylcholine and phosphatidylethanolamine. In phosphatidylcholine, total n-6 tetraenoic very-long-chain fatty acids and total n-3 pentaenoic and n-3 hexaenoic very-long-chain fatty acids increased after feeding AA and DHA, respectively. Developmental changes were characterized by a decrease in 20:4n-6 in the major phospholipids,
\end{abstract}

\section{ABSTRACT}

whereas 22:6n-3 increased with age in rod outer segments. The highest rhodopsin content occurred in the retina of rats fed diets containing AA and/or DHA. The kinetics of rhodopsin disappearance after light exposure was highest in rats fed DHA at 6 wk of age. This study demonstrates that small manipulations of the dietary level of 20:4n-6 and 22:6n-3 are important determinants of fatty acid composition of membrane lipid and visual pigment content and kinetics in the developing photoreceptor cell. (Pediatr Res 48: 524-530, 2000)

$\quad$ Abbreviations
AA, arachidonic acid (20:4n-6)
DHA, docosahexaenoic acid (22:6n-3)
LA, linoleic acid (18:2n-6)
LNA, $\alpha$-linolenic acid (18:3n-3)
LCFA, long-chain fatty acids (C20-C22)
PC, phosphatidylcholine
PE, phosphatidylethanolamine
PS, phosphatidylserine
ROS, rod outer segment
VLCFA, very-long-chain fatty acids (C24-C36)

Functions of the retina, measured by electroretinogram and visual evoked potentials, may mature earlier when infants are fed a nutritional regime containing 20:4n-6 and 22:6n-3 (1-4). Deficiency of 18:3n-3 is associated with loss of visual function (5-7). These functional changes in the retina are believed to be caused in some way by change occurring in the fatty acid

Received May 20, 1999; accepted March 13, 2000.

Correspondence: M. Thomas Clandinin, Ph.D., Nutrition and Metabolism Research Group, Departments of Agricultural, Food, and Nutritional Science and Department of Medicine, University of Alberta, 4-10 Agriculture/Forestry Centre, Edmonton, Alberta, Canada T6G 2P5.

Supported by the Natural Sciences and Engineering Research Council of Canada and Wyeth Nutritionals International. constituents of phospholipids in the retinal system associated with visual function. Increased dietary intake of n-3 fatty acids increases the n-3 fatty acid content of the $\operatorname{ROS}(8,9)$. The subcellular localization and mechanisms linking change in structural components of the retina to specific functional changes are not known. It is reasonable to speculate that the mechanisms involve the photoreceptor cell and perhaps rhodopsin.

Development of the visual system follows a sequence of events involving synthesis of complex lipids to provide basic membrane structural components (10). Retina membrane phospholipids, particularly PE, contain high levels of 22:6n-3 (11, 
12). Significant amounts of PS and PC also occur in the ROS of the retina (8). These two phospholipids contain VLCFA from C24-C34 carbons in chain length of both $n-6$ and n-3 type $(8,13)$ in addition to DHA. The biologic function and role of these very-long-chain components is not known.

Exposure to light stimulates turnover and recycling of membrane components in the ROS of the retina $(14,15)$. The ROS is the major photon-capturing device that consists of a stack of disk-shaped double membrane lipid bilayers where rhodopsin is densely packaged as intrinsic transmembrane proteins. Delipidated rhodopsin is not able to regenerate rhodopsin, but the regeneration is restored by addition of phospholipids (16). Rats fed an n-3 fatty acid diet exhibit lower rhodopsin regeneration than when fed a soybean oil (17), suggesting that rhodopsin function requires specific lipid components. During development, the ROS undergoes a transition in the composition of membrane phospholipids (18). These compositional changes may occur in concert with transitions in functions involving rhodopsin and the response of rhodopsin to light exposure.

Thus, the present study was designed to examine the developmental change that occurs in the fatty acid composition of the ROS after feeding diet fats that reflect the fatty acid composition of potential infant formulas. To achieve this objective, retinas were isolated from rats fed these diets for up to $6 \mathrm{wk}$ of life. The effect of diet treatment and developmental age on the fatty acid content of individual phospholipids, rhodopsin content, and rhodopsin kinetics in response to exposure of ROS to light was also examined.

\section{METHODS}

\section{Rats and Diets}

Albino Sprague-Dawley rats were obtained for breeding from the University of Alberta vivarium. The condition of breeding and rearing pups has been described in detail previously (18). The light intensity of the rearing animal room was 400 lux. Experimental diets were fed to dams after delivery of the rat pups. All litters were culled to 12 rats within $24 \mathrm{~h}$ after parturition. Pups were killed by decapitation in the dark at 2, 3, and $6 \mathrm{wk}$ of age. This study was approved by the University of Alberta Animal Ethics Committee.

Five semipurified experimental diets containing 20\% (wt/ wt) fat and varying in fat composition were fed (Table 1) (19). Diet fats were formulated to reflect the fat composition of a conventional infant formula providing an 18:2n-6 to $18: 3 n-3$ ratio of 7:1 (control fat blend; SMA, Wyeth Nutritionals International, Radnor, PA, U.S.A.). 22:6n-3 and 20:4n-6 were not present in this fat blend. Three experimental diets were prepared by addition of various triglycerides to provide AA and DHA in the basic control fat blend as follows: 1) control fat blend was modified to contain $1 \%$ (wt/wt) AA; 2) control fat blend was modified to contain $0.6 \%$ (wt/wt) DHA; 3) control fat blend was modified to contain both $1 \%(\mathrm{wt} / \mathrm{wt}) \mathrm{AA}$ and $0.6 \%(\mathrm{wt} / \mathrm{wt}$ ) DHA (Table 1). Another diet was formulated to increase the level of $18: 3 n-3$ to provide an $18: 2 n-6$ to $18: 3 n-3$ ratio of $4: 1$. The AA and DHA triglycerides used were obtained from single cell oils (Martek Biosciences, Columbia, MD, U.S.A.).

\section{Isolation of Retina and ROS}

All procedures were performed at $4^{\circ} \mathrm{C}$ under dim red light. Retinas were isolated (20) from rats that were dark-adapted overnight. Twelve retinas from one litter were pooled for separation of the ROS by discontinuous sucrose gradient centrifugation (21). Sample purification of ROS was evaluated as described previously (8).

\section{Lipid Analysis}

Lipids from ROS were extracted and partitioned according to the procedure of Folch et al. (22). All organic solvent used contained $1 \mathrm{ppm}$ ethoxyquin. Phospholipid classes were separated as described before (8), and fatty acid methyl esters were prepared with $14 \%$ (wt/wt) $\mathrm{BF}_{3}$-methanol (23).

\section{Analysis of Fatty Acid Methyl Esters}

Fatty acid methyl esters were separated on a polar BPX70 column $(25 \mathrm{~m} \times 0.22 \mathrm{~mm}$ ID) using a Hewlett Packard 5890

Table 1. Fatty acid composition of experimental diets

\begin{tabular}{|c|c|c|c|c|c|}
\hline $\begin{array}{l}\text { Diet Fatty acid } \\
(\% \mathrm{wt} / \mathrm{wt})\end{array}$ & Control* & $\mathrm{AA} \dagger$ & $\mathrm{DHA}_{\dagger} \dagger$ & $\mathrm{AA}+\mathrm{DHA} \uparrow$ & $\mathrm{LA} / \mathrm{LNA}=4: 1 \ddagger$ \\
\hline 14:0 & 5.4 & 5.3 & 5.6 & 5.4 & 5.2 \\
\hline $16: 0$ & 13.3 & 13.4 & 13.2 & 13.2 & 13.0 \\
\hline $18: 1 n-7+n-9$ & 39.8 & 39.1 & 39.5 & 38.6 & 39.2 \\
\hline $18: 2 n-6$ & 16.8 & 16.7 & 16.4 & 16.5 & 16.9 \\
\hline $18: 3 n-3$ & 2.4 & 2.4 & 2.4 & 2.3 & 4.1 \\
\hline ¿SAT & 38.4 & 38.5 & 38.3 & 38.4 & 37.4 \\
\hline ¿Mono & 42.1 & 41.1 & 41.8 & 40.7 & 41.4 \\
\hline$\sum n-6$ & 16.8 & 17.8 & 16.5 & 17.7 & 16.9 \\
\hline$\sum n-3$ & 2.6 & 2.6 & 3.4 & 3.1 & 4.1 \\
\hline $18: 2 n-6 / 18: 3 n-3$ & 7.0 & 7.1 & 6.9 & 7.1 & 4.1 \\
\hline
\end{tabular}

* Fatty acid composition of the fat blend of an existing infant formula. $†$ Control fat blend with addition of AA, DHA, or AA and DHA mixture. $\$$ Control fat blend with increased level of LNA. Abbreviations: $\Sigma$ SAT, total saturated fatty acids; $\Sigma$ Mono, total monounsaturated fatty acids; $\Sigma$ n-6, total n-6 fatty acids; $\Sigma \mathrm{n}-3$, total n-3 fatty acids. Both $\mathrm{C} 24: 0$ and $\mathrm{C} 24: 1$ exist $<0.18 \%(\mathrm{wt} / \mathrm{wt})$ in each diet. 
GLC equipped with a Vista DS 654 data system, as described earlier (8). Data were expressed as a percentage of the area count for an individual fatty acid relative to all fatty acids combined with no response factor correction.

\section{Rhodopsin Measurement}

Rhodopsin content and kinetics from retinas of each dietary group were determined in 2-, 3-, and 6-wk-old rats. Rats were dark-adapted overnight for 12 to $14 \mathrm{~h}$ before removing the retina. Care was given to carry out all procedures in complete darkness or in dim red light. After isolation, retinas were immediately frozen in liquid nitrogen and stored at $-70^{\circ} \mathrm{C}$ until analysis. Rhodopsin was extracted from retinal homogenate by addition of $0.45 \mathrm{~mL}$ of $1 \%(\mathrm{wt} / \mathrm{vol}) n$-octyl-B-Dglucopyranoside in $0.067 \mathrm{M}$ phosphate buffer $(\mathrm{pH}$ 6.7) as described by Fulton et al. (24). An aliquot of the homogenate was taken for protein analysis (25). Each extract was scanned from 270 to $700 \mathrm{~nm}$ using a Hewlett Packard 8452A diodearray spectrophotometer in the complete darkness and then scanned at $5,10,15,30,60,120,180,240$, and $360 \mathrm{~s}$ during bleaching with a cool white fluorescent light (26) with the intensity of 1000 lux (14.4 Quantum, $\mu \mathrm{Em}^{2} \mathrm{~s}^{-1}$ ) at a distance of $30 \mathrm{~cm}$ from the cuvette. Rhodopsin level was calculated by the change in absorption at $498 \mathrm{~nm}$ before and after bleaching for $360 \mathrm{~s}$. A molar extinction coefficient of 40,000 (27) was used for conversion of the measured OD to concentration. The measurement at each time point was used to calculate the kinetics of rhodopsin bleaching.

\section{Statistical Analysis}

The effect of diet and age on the fatty acid composition of phospholipid in the ROS and on the rhodopsin content of the retina was analyzed by 2-way ANOVA with diet and age as the main factors. The test of the main factors was based on the comparison by least square means. The analysis tool was SAS statistical software (28). All data are expressed as mean \pm SEM.

\section{RESULTS}

All pups grew normally in body weight during the experiment. By 6 wk of age, rats from all diet treatments had similar body weights except for rats fed an LA/LNA ratio of 4:1. These rats showed a significantly lower body weight.

\section{Effect of Dietary Fat on Fatty Acid Composition of ROS}

Dietary fat significantly altered the fatty acid composition of the major phospholipids of dark-adapted ROS of 2-, 3-, and 6-wk-old rats. In all phospholipids, total saturated and monounsaturated fatty acid content was maximal at 2 wk and then decreased by time of weaning (data not shown). By $6 \mathrm{wk}$ of age, total saturated fatty acid content increased from weaning but not to the level observed for 2 -wk-old rats. Total monounsaturated fatty acid decreased further (data not shown). The results illustrated focus on the level of 20:4n-6, 22:6n-3 and n-6 and n-3 VLCFA (Tables 2 and 3).

Table 2. Effect of dietary supply of 20:4n-6 and 22:6n-3 on the level of 20:4n-6 and 22:6n-3 in phospholipids of ROS of 2-, 3-, and 6-wk-old rats

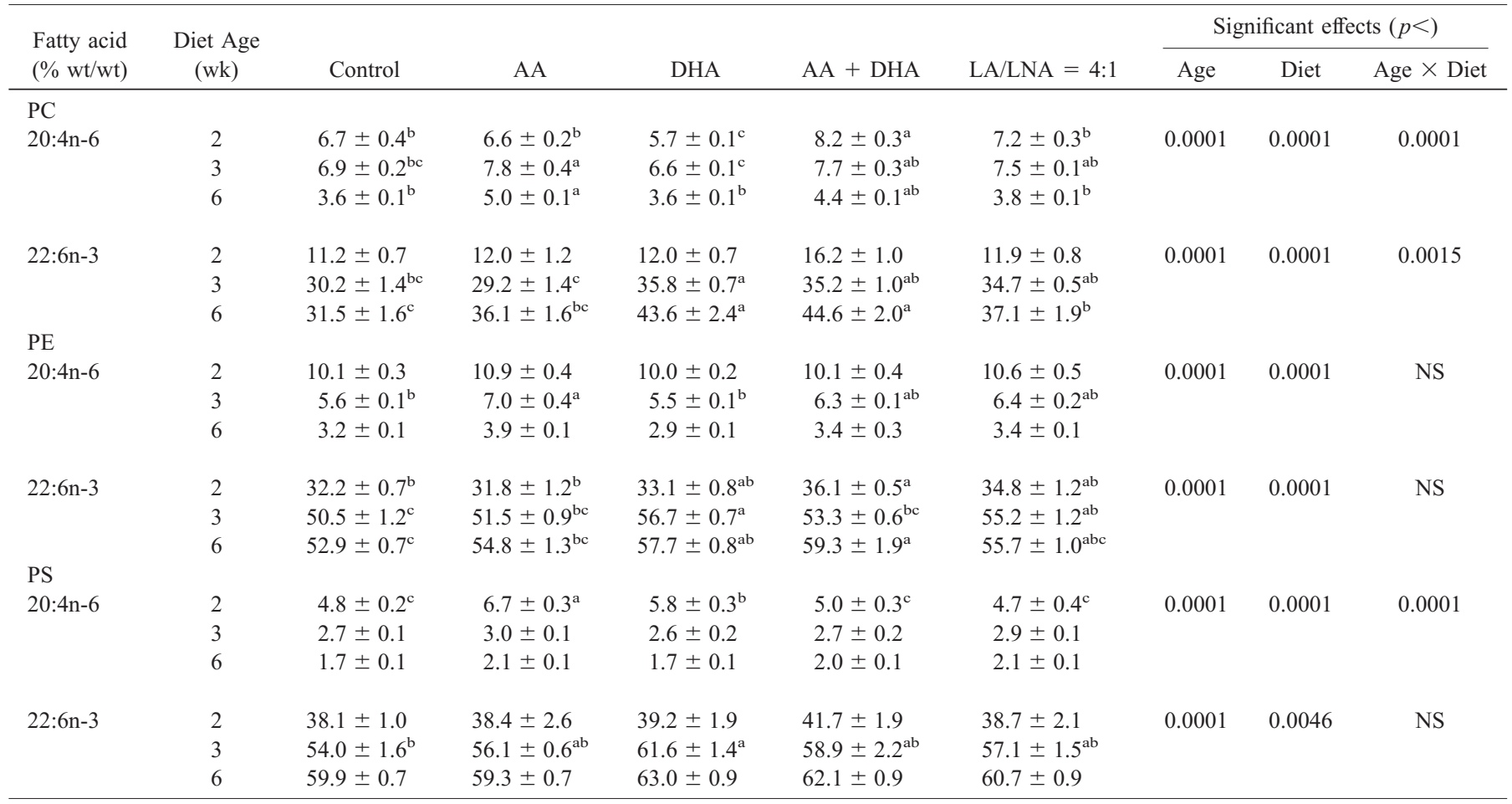

Values are group mean ( $n=5$ or 6$) \pm$ SEM. For each $n, 12$ retinas were pooled. Significant effects were identified by 2 -way ANOVA for age and diet. Values within a row having a different superscript indicate that diet group within each age is different by comparison of least squares means, $p<0.01$. Each experimental diet group was compared with the control diet group for each age. 
Table 3. Effect of dietary content of 20:4n-6 and 22:6n-3 on the level of C32 and C34 VLCFA in PC of ROS of 6-wk-old rats

\begin{tabular}{|c|c|c|c|c|c|c|}
\hline $\begin{array}{c}\text { Diets Fatty } \\
\text { acids (\% wt/wt) }\end{array}$ & Control & AA & DHA & $\mathrm{AA}+\mathrm{DHA}$ & $\mathrm{LA} / \mathrm{LNA}=4: 1$ & $\begin{array}{c}\text { Effect of diet } \\
\quad(p<)\end{array}$ \\
\hline \multicolumn{7}{|l|}{ n-6 VLCFA } \\
\hline C32:4 & $0.56 \pm 0.06^{\mathrm{ab}}$ & $0.61 \pm 0.07^{\mathrm{a}}$ & $0.52 \pm 0.04^{\mathrm{b}}$ & $0.62 \pm 0.05^{\mathrm{a}}$ & $0.51 \pm 0.02^{\mathrm{b}}$ & 0.0034 \\
\hline $\mathrm{C} 32: 5$ & $0.06 \pm 0.01^{\mathrm{a}}$ & $0.07 \pm 0.01^{\mathrm{a}}$ & $0.02 \pm 0.00^{\mathrm{b}}$ & $0.03 \pm 0.00^{\mathrm{b}}$ & $0.03 \pm 0.00^{\mathrm{b}}$ & 0.001 \\
\hline $\mathrm{C} 34: 5$ & $0.03 \pm 0.00$ & $0.04 \pm 0.01$ & $0.08 \pm 0.03$ & $0.02 \pm 0.00$ & $0.03 \pm 0.01$ & NS \\
\hline$\Sigma$ n-6 VLCFA & $1.39 \pm 0.14^{\mathrm{b}}$ & $1.63 \pm 0.12^{\mathrm{a}}$ & $1.33 \pm 0.09^{\mathrm{b}}$ & $1.45 \pm 0.11^{\mathrm{ab}}$ & $1.35 \pm 0.07^{\mathrm{b}}$ & 0.0001 \\
\hline $\mathrm{C} 34: 5$ & $0.50 \pm 0.03^{b c}$ & $0.41 \pm 0.04^{\mathrm{c}}$ & $0.69 \pm 0.05^{\mathrm{a}}$ & $0.58 \pm 0.02^{\mathrm{ab}}$ & $0.62 \pm 0.04^{\mathrm{ab}}$ & 0.0008 \\
\hline $\mathrm{C} 32: 6$ & $1.67 \pm 0.23^{\mathrm{b}}$ & $1.24 \pm 0.12^{\mathrm{c}}$ & $2.20 \pm 0.12^{\mathrm{a}}$ & $1.93 \pm 0.08^{\mathrm{ab}}$ & $1.83 \pm 0.14^{\mathrm{b}}$ & 0.0001 \\
\hline C34:6 & $1.46 \pm 0.16^{\mathrm{b}}$ & $1.34 \pm 0.12^{\mathrm{b}}$ & $2.14 \pm 0.21^{\mathrm{a}}$ & $2.03 \pm 0.08^{\mathrm{a}}$ & $1.97 \pm 0.10^{\mathrm{a}}$ & 0.0008 \\
\hline$\sum n-3$ VLCFA & $5.07 \pm 0.54^{\mathrm{bc}}$ & $4.13 \pm 0.33^{c}$ & $6.63 \pm 0.42^{\mathrm{a}}$ & $5.92 \pm 0.22^{\mathrm{ab}}$ & $5.72 \pm 0.36^{\mathrm{ab}}$ & 0.0001 \\
\hline
\end{tabular}

Values are group mean $(n=6) \pm$ SEM. For each $n, 12$ retinas were pooled. P values are obtained from 2-way ANOVA for age and diet. Significant effects of age were identified for the above fatty acids except 34:5n-6 $(p<0.005)$. Significant interactions were found in all $\mathrm{n}-3$ VLCFA in above. Values within a row having a different superscript are different by comparison of least squares means at the level of $p<0.01$ except 32:4n-6, 34:4n-6, and $\Sigma \mathrm{n}-6$ VLCFA at $p<0.05$.

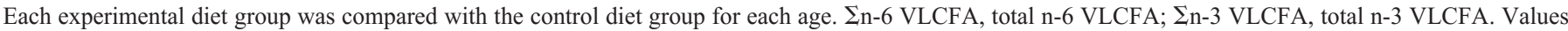
of 2 and $3 \mathrm{wk}$ are not listed in this table.

\section{Effect of Dietary Fatty Acids on Membrane Phospholipids}

PC. Supplying small amounts of 20:4n-6 in the diet increased the level of 20:4n-6 (Table 2) at 3 and 6 wk of age. At these ages, inclusion of 22:6n-3 in the diet increased the level of 22:6n-3. The diet containing an LA/LNA ratio of $4: 1$ showed a comparable level of 22:6n-3 to the diet providing DHA and AA + DHA at the 3-wk stage. However, 22:6n-3 in the LA/LNA diet group did not increase to the level observed at 6 wk of age when animals were fed the DHA and AA + DHA diets. During the experiment period, the accretion of 22:6n-3 increased 2.6-fold between 2 and 3 wk of age and further increased by $6 \mathrm{wk}$. The level of 20:4n-6 decreased between weaning and $6 \mathrm{wk}$ in all diet groups.

$\boldsymbol{P E}$. A greater level of 22:6n-3 in PE was observed at 2 and 6 wk of age after feeding a mixture of AA + DHA in the diet (Table 2) compared with control animals fed the diet. Providing DHA in the diet increased the content of 22:6n-3 at 3 and 6 wk of age and decreased 20:4n-6 at 3 wk of age when compared with rats from the other diet treatments. The ROS from rats fed the control or the AA diet contained the lowest level of 22:6n-3. Continuous decrease in 20:4n-6 content was observed from 2 to $6 \mathrm{wk}$ of age. The overall decrease in $20: 4 n-6$ for rats in all diet groups from preweaning to weaning was $40.5 \%$. During this period, the level of $22: 6 n-3$ increased 1.6-fold.

PS. The 22:6n-3 content of PS was more than 50 to $60 \%$ (wt/wt) (Table 2), the highest among all phospholipids in the ROS. Higher content of $22: 6 \mathrm{n}-3$ at 3 wk of age was found when DHA was provided in the diet compared with animals fed the control diet. The characteristic changes exhibited in 20:4n-6 and 22:6n-3 over the experimental period were similar to those occurring in PE. Decrease in the level of 20:4n-6 from 2 to $3 \mathrm{wk}$ was $47.7 \%$. The 22:6n-3 level increased during this period.

$\boldsymbol{V L C F A}$. In the ROS, VLCFA of n-6 and n-3 homologues with a carbon chain length of up to C36 exist exclusively in PC. Predominant among these fatty acids were n- 6 tetraenoic and n-3 pentaenoic and hexaenoic fatty acid of $\mathrm{C} 32$ and $\mathrm{C} 34$ carbons in chain length. The level of $n-6$ pentaenoic VLCFA was minor. These observations characterize all ages examined. Levels of these VLCFA at $6 \mathrm{wk}$ of age were significantly affected by the dietary fatty acid supplied (Table 3 ). Providing rats with $\mathrm{AA}$ or $\mathrm{AA}+\mathrm{DHA}$ in the diet resulted in increased levels of $32: 4 n-6$ and $34: 4 n-6$ compared with animals fed the DHA diet. The level of 32:5n-6 was higher after feeding the AA diet. Supplying AA in the diet increased total n-6 VLCFA compared with animals fed the control diet. This pattern was also recognized at 2 and $3 \mathrm{wk}$ of age (data not shown). Conversely, inclusion of DHA or AA + DHA in the diet increased the n-3 pentaenoic and hexaenoic fatty acid of C32 and C34 carbons in chain length compared with animals fed the control diet. Animals fed the control diet or the AA diet exhibited the lowest level of n-3 VLCFA by 6 wk of age. Feeding an LA/LNA ratio of 4:1 in the diet resulted in a lower level of $n-6$ tetraenoic and pentaenoic VLCFA compared with animals fed the AA diet. Raising 18:3n-3 from an LA/LNA ratio of $7: 1$ to $4: 1$ in the diet does not increase the level of $22: 6 n-3,32: 5 n-3$, and 32:6n-3 present in growing visual cells by 6 wk of age.

\section{Changes in LCFA and VLCFA Content of the ROS with Developmental Age}

Accretion of both total $n-6$ tetraenoic and n-3 pentaenoic and VLCFA more than doubled in PC between 2 and 3 wk of age and then increased further by $6 \mathrm{wk}$ of age (Fig. 1). During these periods, feeding AA in the diet increased the level of total n-6 tetraenoic VLCFA in the ROS compared with feeding DHA or feeding the diet providing an LA/LNA ratio of 4:1. Providing rats with DHA in the diet increased total n-3 pentaenoic and hexaenoic VLCFA in the ROS at all ages examined. Total n-6 pentaenoic VLCFA decreased in the ROS from weaning to 6 wk of age.

Developmental change in the level of 22:6n-3 to 20:4n-6 and n-3/n-6 VLCFA was also examined in the ROS phospholipids. During development, the ratio of 22:6n-3 to 20:4n-6 increased 

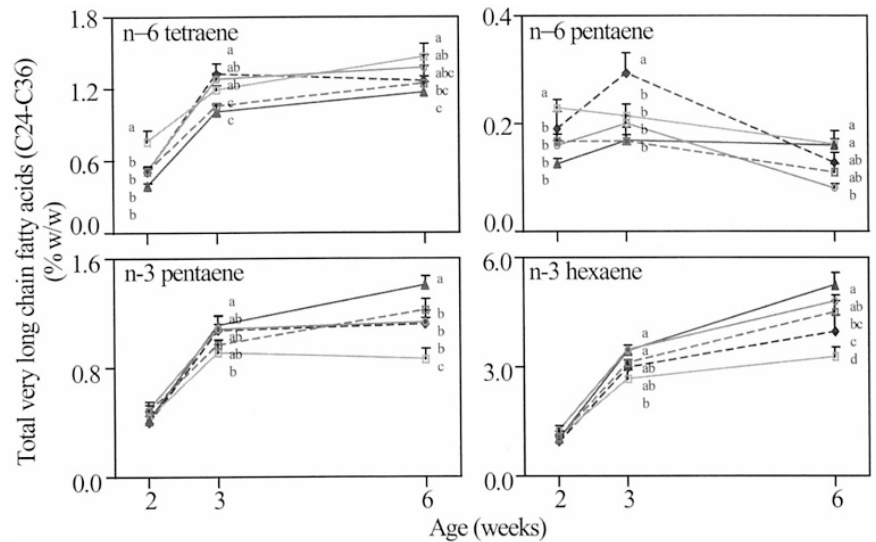

Figure 1. VLCFA (C24-C36) content in PC of ROS of rat retina after supplying 20:4n-6 and 22:6n-3 in diet at 2, 3, and 6 wk of age. Values given are mean $(n=6) \pm$ SEM. For each $n, 12$ retinas were pooled. Values without a common letter within each age are significantly different, $p<0.05$. Significant effects were identified by 2 -way ANOVA for age $(p<0.0001)$ and diet $(p<0.0005)$ in each VLCFA homologue. - $\square$ - indicates control; - $\square$-, AA; - $\mathbf{\Delta -}$-, DHA; - - , AA + DHA; - $\square$-, LA/LNA $=4: 1$.
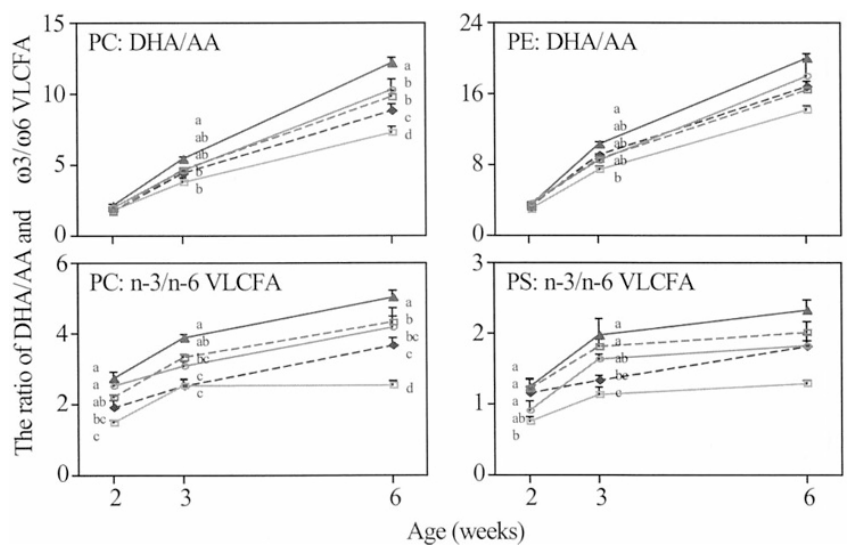

Figure 2. Ratio of $22: 6 n-3$ to $20: 4 n-6$ and n- 3 to n-6 VLCFA in phospholipids of ROS of rat retina after supplying 20:4n-6 and 22:6n-3 in diet at 2, 3, and $6 \mathrm{wk}$ of age. Values given are mean $(n=5$ or 6$) \pm$ SEM. For each $n, 12$ retinas were pooled. Values without a common letter within each age are significantly different, $p<0.05$. Significant effects were identified by 2-way ANOVA for age $(p<0.0001)$ and diet $(p<0.0001)$ in each ratio. DHA/AA indicates the ratio of DHA to AA; $P C: n-3 / n-6 V L C F A$, the ratio of total n-3 to total n-6 VLCFA (C24-C36); PS: $n-3 / n-6 V L C F A$, the ratio of total n-3 to total n-6

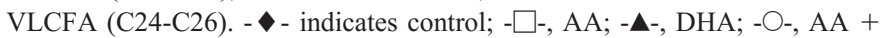
DHA; - $\square$-, LA/LNA $=4: 1$.

in PC, PE (Fig. 2), and PS (data not shown). The highest ratio of 22:6n-3 to 20:4n-6 was found in rats fed the diet containing DHA. The ratio of n-3 VLCFA to n-6 VLCFA also increased with age in PC and PS. Inclusion of a small amount of DHA in the diet resulted in the highest ratio of n-3 VLCFA to $n-6$ VLCFA in PC and PS, whereas the lowest ratio was observed in the ROS of rats fed the diet containing AA.

\section{Effect of Dietary Fatty Acids on the Rhodopsin Content of the ROS}

The rhodopsin content in the retina increased with age when expressed as nmol/mg protein (Fig. 3). For example, the retina from rats fed a diet containing AA + DHA was 1.6 times higher in rhodopsin content at weaning $(0.70 \pm 0.08 \mathrm{nmol} / \mathrm{mg}$

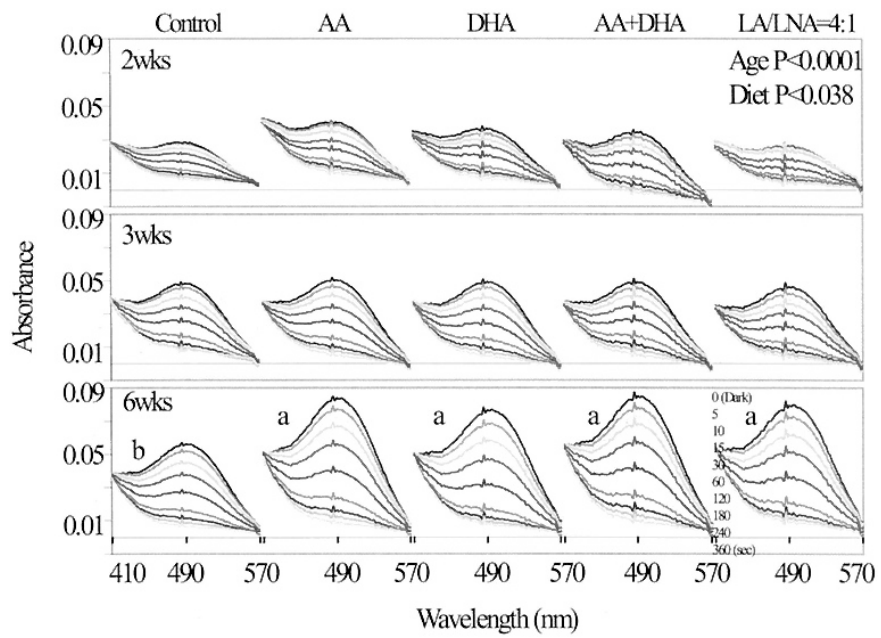

Figure 3. The absorption spectrum from 410 to $570 \mathrm{~nm}$ for retinal rhodopsin from rats fed experimental diets for 2, 3, and $6 \mathrm{wk}$. Each spectrum represents mean $(n=5$ or 6$)$. Significant effects were identified by 2-way ANOVA for age and diet. Spectra without a common letter in $6 \mathrm{wk}$ are different by comparison with least squares means, $p<0.05$. The level of rhodopsin was calculated by the change in absorption at $498 \mathrm{~nm}$ before and after bleaching for $360 \mathrm{~s}$. The rhodopsin levels (nmol/mg protein, mean \pm SEM) for 2-, 3-, and 6-wk-old rats fed the control, AA, DHA, AA + DHA, or LA/LNA $=4: 1$ diet, respectively, are as follows: $2 \mathrm{wk}, 0.36 \pm 0.04,0.42 \pm 0.03,0.42 \pm 0.01$, $0.45 \pm 0.01,0.36 \pm 0.04 ; 3 \mathrm{wk}, 0.62 \pm 0.07,0.62 \pm 0.09,0.65 \pm 0.06,0.70 \pm$ $0.08,0.72 \pm 0.05 ; 6 \mathrm{wk}, 0.77 \pm 0.07,1.00 \pm 0.06,1.02 \pm 0.03,1.02 \pm 0.05$, $0.95 \pm 0.07$. The measurement at each time point, $0,5,10,15,30,60,120$, 180,240 , and $360 \mathrm{~s}$, was used to calculate the kinetics of rhodopsin bleaching illustrated in Figure 4.

protein) than before weaning $(0.45 \pm 0.01 \mathrm{nmol} / \mathrm{mg}$ protein $)$. Rhodopsin content increased to $1.02 \pm 0.03 \mathrm{nmol} / \mathrm{mg}$ protein by $6 \mathrm{wk}$ of age. The highest rhodopsin content occurred in the retina of rats fed diets containing a small amount of AA and/or DHA at $6 \mathrm{wk}$ of age. Providing animals with LA/LNA $=4: 1$ also increased rhodopsin content compared with the animals fed the control diet. Compared with the rhodopsin content in the rats fed the control considered as 1 , the highest relative content of rhodopsin was exhibited by rats fed the fat mixture containing AA + DHA at 2, 3, and 6 wk of age. Providing rats with DHA in the diet also produced higher rhodopsin content at 2 and 6 wk of age. Although no significant difference was found, diet providing an LA/LNA ratio of $4: 1$ exhibited the lowest relative rhodopsin content at 2 and 6 wk of age $(0.99$ and 1.23 , respectively) compared with the other experimental diets.

\section{Effect of Dietary Fat on Rhodopsin Kinetics}

The effect of dietary fat treatment on the kinetics of rhodopsin disappearance at $6 \mathrm{wk}$ of age was significant $(p<0.05)$. Rhodopsin disappearance after bleaching is illustrated for each diet group (Fig. 4). The rate constant ( $k$ ) of rhodopsin disappearance was represented by the slope determined (Fig. 4). The kinetics of rhodopsin bleaching after light exposure was the greatest in rats fed a small quantity of DHA $(k, 0.0030)$, followed by rats fed the diet providing an LA/LNA ratio of $4: 1$ $(k, 0.0028)$. During bleaching for $360 \mathrm{~s}$, rhodopsin disappeared in a short time $\left(p<0.05\right.$; half-life, $\left.38.5 \pm 1.4^{\mathrm{b}} \mathrm{s}\right)$ from rats fed the diet containing DHA compared with the rate of disappear- 


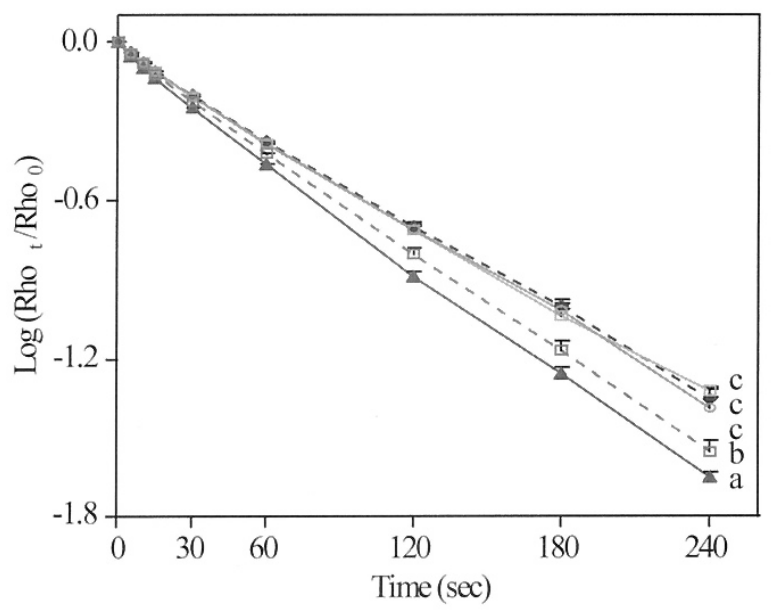

Figure 4. Effect of dietary content of $20: 4 n-6$ and $22: 6 n-3$ on the kinetics of rhodopsin disappearance in rat retina at $6 \mathrm{wk}$ of age. Rhodopsin was bleached for $5,10,15,30,60,120,180,240$, and $360 \mathrm{~s}$. The $\mathrm{y}$ axis is the log of the rhodopsin bleached. Significant effects of diet were tested by least squares means comparison, $p<0.05$. The time (seconds) of half-life of rhodopsin is also significantly different at $p<0.05$. The half-life of rhodopsin and the rate constants $(k)$ of rhodopsin disappearance for diet treatments, control, AA, $\mathrm{DHA}, \mathrm{AA}+\mathrm{DHA}$, and LA/LNA $=4: 1$, respectively, are as follows (mean \pm SEM, $n=5$ or 6 ): half-life (seconds), $48.7 \pm 2.3^{\mathrm{a}}, 47.2 \pm 0.7^{\mathrm{a}}, 38.5 \pm 1.4^{\mathrm{b}}$, $47.9 \pm 1.5^{\mathrm{a}}, 43.2 \pm 1.4^{\mathrm{ab}}$; rate constants ( $k$, mean), 0.0024, 0.0024, 0.0030, $0.0025,0.0028$. Rho $o_{t}$ indicates dark-adapted rhodopsin; Rho $o_{0}$, bleached rhodopsin at time t. - $\bullet$ - indicates control; - $\square$-, AA; - $\mathbf{\Delta - ,}$ DHA; -O-, AA + DHA; $-\square-$, LA/LNA $=4: 1$.

ance observed for rats fed the other diets $\left(48.7 \pm 2.3^{\mathrm{a}}, 47.2 \pm\right.$ $0.7^{\mathrm{a}}, 47.9 \pm 1.5^{\mathrm{a}}, 43.2 \pm 1.4^{\mathrm{ab}}$ for control, AA, AA + DHA, and $\mathrm{LA} / \mathrm{LNA}=4: 1$, respectively).

\section{DISCUSSION}

\section{Relationship between Dietary Fat and LCFA Composition}

Correlation between DHA intake and visual function has been well documented $(7,29)$. Studies in animal models have used extremely unbalanced n- 6 to n-3 fatty acid ratios ranging from 32 to 255 to 1 . The present study demonstrates that small changes in dietary level of AA and/or DHA within the physiologic intake range (30) are important determinants of visual cell membrane fatty acid composition during development of the retina. Diet-induced alterations of membrane fatty acid composition have significant implications for early retinal development in relation to the function of rhodopsin. Fatty acids consumed by the neonate are associated with change in visual cell maturation and visual function $(1,31-33)$. It is important to note that functional loss occurring during development may not be restored in later life even when the deficient fat component is restored (34).

In the present study, supplying a diet containing both AA and DHA increased levels of both 20:4n-6 and 22:6n-3 in phospholipid of growing visual cells, comparable in ROS to that of rats fed a diet containing DHA or AA alone. Addition of AA to a diet containing DHA did not apparently compete with the other for acylation into membrane phospholipid. This may be partly explained by the fact that these two fatty acids are typical components of dipolyunsaturated molecular species of phospholipids of photoreceptor membrane $(35,36)$, which account for approximately $30 \%$ of the total lipid content. A physiologic level of intake of DHA increased 22:6n-3, which caused a reduction in level of 20:4n-6 in but not in the level of 20:4n-6 in PE and PS.

Retina possesses the enzymatic system to elongate and desaturate $18: 3 n-3$ to $22: 6 n-3$ (37). It appears that feeding preformed DHA or AA better supports the increase in 20:4n-6 and 22:6n-3 level in the growing retina compared with feeding LNA without AA + DHA. It has been reported that $22: 6 n-3$ is the preferred fatty acid for raising the level of 22:6n-3 in the retina $(38,39)$. When animals are deficient in LNA, supplementing with a source of LNA will increase the level of 22:6n-3 compared with the deficient group $(6,17,40)$.

Developmental change in the fatty acid composition of the retina is a dynamic process during the period of rapid visual cell growth. Levels of polyunsaturated fatty acids in the retina seem to parallel those of liver and plasma (41). From 2 to $6 \mathrm{wk}$ of the experimental period, there was an increase in the level of $22: 6 n-3$ as a function of age. This experiment provides evidence that the photoreceptor membrane fatty acid composition shifts from a saturated to a more unsaturated fatty acid environment. This shift during maturation of visual cells is likely related to the change that occurs in the functional development of the retina.

\section{Relationship between Dietary Fatty Acids and VLCFA Composition}

This experiment provides evidence for a response of VLCFA to diet treatment during development of the photoreceptor. In animals fed the AA + DHA diet, the level of total n- 6 and n-3 VLCFA was $2.4 \%$ at $2 \mathrm{wk}, 6 \%$ at $3 \mathrm{wk}$, and $7.3 \%$ at 6 wk.

These data are similar to those previously reported for neonatal rat and human fetal brain at $24 \mathrm{wk}$ of gestation in that n- 6 pentaenoic VLCFA predominate and that no n- 6 VLCFA are present beyond the neonatal period $(42,43)$. The $n-6$ with the increased ratio of $22: 6 n-3$ is characterized by a transition in the photoreceptor cell fatty acid composition toward higher n-3 fatty acid content.

\section{Relationship between Dietary Fatty Acids and Rhodopsin}

To evaluate the relationship between dietary fatty acids and retinal function, rhodopsin content and rhodopsin disappearance kinetics were evaluated after light exposure. The value for rhodopsin at $6 \mathrm{wk}$ of age lies within the range of values for whole eye rhodopsin level reported in the literature for similar body weights (44). The level of rhodopsin at $9 \mathrm{wk}$ of age is between 1.5 and $1.7 \mathrm{nmol} / \mathrm{mg}$ protein (submitted for publication), implying that the retinas used in this experiment are still developing. An increasing level of rhodopsin was reported up to $24 \mathrm{wk}$ of age (17). The developmental increase in rhodopsin is also associated with increasing levels of $22: 6 n-3$ and VLCFA. The highest relative content of rhodopsin is exhibited by rats fed $\mathrm{AA}+\mathrm{DHA}$ at 2, 3, and 6 wk of age compared with 
rats fed the control diet. When initially dark-adapted retinas in vivo were exposed to light in vitro, the rhodopsin disappearance kinetics in the retina was quite different depending on the rats' diet (Fig. 4). Rhodopsin disappeared more rapidly after light exposure in rats fed DHA, followed by rats fed a diet providing an LA:LNA ratio of $4: 1$. This supports the earlier suggestion (45) that n-3 fatty acid containing membrane components influences the rhodopsin response to light, perhaps indicating that dietary fat may play a role in providing for the molecular environment for rhodopsin function.

It is concluded that small dietary amounts of AA and DHA are sufficient to influence the membrane LCFA and VLCFA composition in the visual cell during development. Addition of AA or DHA individually in the diet alters the level of 22:6n-3 and VLCFA. A mixture of AA and DHA in the diet supports a balance between n-3 to n-6 fatty acids that seems to be needed to develop the highest rhodopsin content in the ROS. Although functional roles for n-6 and n-3 VLCFA in photoreceptors still remain unclear, developmental relationships apparently exist between rhodopsin function, 22:6n-3, and VLCFA.

\section{REFERENCES}

1. Uauy R, Birch DG, Birch EE, Tyson JE, Hoffman DR 1990 Effect of dietary omega-3 fatty acids on retinal function of very-low-birth-weight neonates. Pediatr Res $28: 485$ 492

2. Birch EE, Birch DG, Hoffman DR, Uauy R 1992 Dietary essential fatty acid supply and visual acuity development. Invest Ophthalmol Vis Sci 33:3242-3253

3. Birch E, Birch D, Hoffman D, Hale L, Everett M, Uauy R 1993 Breast-feeding and optimal visual development. J Pediatr Ophthalmol Strabismus 30:33-38

4. Carlson SE, Werkman SH, Rhodes PG, Tolley EA 1993 Visual-acuity development in healthy preterm infants: effect of marine-oil supplementation. Am J Clin Nutr 58:35-42

5. Neuringer M, Connor WE, Petten CV, Barstad L 1984 Dietary omega-3 fatty acid deficiency and visual loss in infant rhesus monkeys. J Clin Invest 73:272-276

6. Weisinger HS, Vingrys AJ, Bui BV, Sinclair AJ 1999 Effects of dietary n-3 fatty acid deficiency and repletion in the guinea pig retina. Invest Ophthalmol Vis Sci 40:327338

7. Neuringer M, Connor WE, Lin PS, Barstad L, Luck S 1986 Biochemical and functional effects of prenatal and postnatal $\omega 3$ fatty acid deficiency on retina and brain in rhesus monkeys. Proc Natl Acad Sci USA 3:4021-4025

8. Suh M, Wierzbicki AA, Clandinin MT 1994 Dietary fat alters membrane composition in rod outer segments in normal and diabetic rats: impact on content of very-longchain $(C \geq 24)$ polyenoic fatty acids. Biochim Biophys Acta $1214: 54-62$

9. Lin DS, Anderson GJ, Connor WE, Neuringer M 1994 Effect of dietary n-3 fatty acids upon the phospholipid molecular species of the monkey retina. Invest Ophthalmol Vis Sci 35:794-803

10. Jumpsen J, Clandinin MT 1995 Brain Development: Relationship to Dietary Lipid and Lipid Metabolism. AOCS Press, Champaign, IL, pp 45-64

11. Anderson RE, Feldman LS, Feldman GL 1970 Lipids of ocular tissues. V. The phospholipids of mature bovine and rabbit whole retina. Biochim Biophys Acta 202:369-373

12. Nielsen JC, Maude MB, Hughes H, Anderson RE 1986 Rabbit photoreceptor outer segments contain high levels of docosapentaenoic acid. Invest Opthalmol Vis Sci 27:261-264

13. Aveldano MI 1987 A novel group of very-long-chain polyenoic fatty acids in dipolyunsaturated phosphatidylcholines from vertebrate retina. J Biol Chem 262:1172-1179

14. Birkle DL, Bazan NG 1989 Light exposure stimulates arachidonic acid metabolism in intact rat retina and isolated rod outer segments. Neurochem Res 14:185-190

15. Wiegand RD, Koutz CA, Chen H, Anderson RE 1995 Effect of dietary fat and environmental lighting on the phospholipid molecular species of rat photoreceptor membranes. Exp Eye Res 60:291-306

16. Shichi H 1971 Biochemistry of visual pigments. II. Phospholipid requirements and opsin conformation for regeneration of bovine rhodopsin. J Biol Chem 246:6178 6182
17. Bush RA, Malnoe A, Reme CE, Williams TP 1994 Dietary deficiency of n-3 fatty acids alters rhodopsin content and function in the rat retina. Invest Ophthalmol Vis Sci 35:91-100

18. Suh M, Wierzbicki AA, Clandinin MT 1996 Relationship between dietary supply of long-chain fatty acids and membrane composition of long- and very-long-chain essential fatty acids in developing rat photoreceptors. Lipids 31:61-64

19. Clandinin MT, Yamashiro S 1982 Dietary factors affecting the incidence of dietary fat induced myocardial lesions. J Nutr 112:825-828

20. Fumiyuki U, Yasumura D, LaVail MM 1989 New isolation method of retina and interphotoreceptor matrix. Exp Eye Res 49:305-309

21. Stinson AM, Wiegand RD, Anderson RE 1991 Metabolism of lipid molecular species in rat rod outer segments. Exp Eye Res 52:219-227

22. Folch J, Lees M, Sloane-Stanley GH 1957 A simple method for the isolation and purification of total lipids from animal tissues. J Biol Chem 226:497-509

23. Morrison WR, Smith LM 1964 Preparation of fatty acid methyl esters and dimethylacetals from lipids with boron fluoride-methanol. J Lipid Res 5:600-608

24. Fulton AB, Manning KA, Baker BN, Schukar SE, Bailey CJ 1982 Dark-adapted sensitivity, rhodopsin content, and background adaptation in $p c d / p c d$ mice. Invest Opthalmol Vis Sci 22:386-393

25. Lowry OH, Rosebrough NJ, Farr AL, Randall RJ 1951 Protein measurement with Folin phenol reagent. J Biol Chem 193:265-275

26. Kuhn H, Wilden U 1982 Assay of phosphorylation of rhodopsin in vitro and in vivo. Methods Enzymol 81:489-496

27. Hubbard R, Brown PK, Bownds D 1971 Methodology of vitamin A and retinal pigments. Methods Enzymol 18:615-653

28. SAS Institute, Inc. 1985 User's Guide: Statistics, Version 5. SAS Institute, Inc., Cary, $\mathrm{NC}$

29. Pawlosky RJ, Denkins Y, Ward G, Salem Jr N 1997 Retinal and brain accretion of long-chain polyunsaturated fatty acids in developing felines: the effects of corn oil-based maternal diets. Am J Clin Nutr 65:465-472

30. Clandinin MT, Garg ML, Parrott A, Aerde JV, Hervada A, Lien E 1992 Addition of long-chain polyunsaturated fatty acids to formula for very low birth weight infants. Lipids 27:896-900

31. Uauy R, Birch EE, Birch DG, Peirano P 1992 Visual and brain function measurements in studies of n-3 fatty acid requirements of infants. J Pediatr 120:S168 -S180

32. Werkman SH, Carlson SE 1996 A randomized trial of visual attention of preterm infants fed docosahexaenoic acid until nine months. Lipids 31:91-97

33. Faldella G, Govoni M, Alessandroni R, Marchiani E, Paolo S, Biagi PL, Spano C 1996 Visual evoked potentials and dietary long-chain polyunsaturated fatty acids in preterm infants. Arch Dis Child 75:F108-F112

34. Neuringer M, Connor WE 1989 Omega-3 fatty acids in the retina. In: Galli C, Simopolos AP (eds) Dietary Omega-3 and Omega-6 Fatty Acids. Plenum Press, New York, pp 177-190

35. Aveldano MI, Bazan NG 1983 Molecular species of phosphatidylcholine, phosphatidylethanolamine, phosphatidylserine, and phosphatidylinositol in microsomal and photoreceptor membranes of bovine retina. J Lipid Res 24:620-627

36. Aveldano MI 1989 Dipolyunsaturated species of retina phospholipids and their fatty acids. In: Leger CL, Bereziat G (eds) Biomembranes and Nutrition: Nutrients Affecting Lipid Composition Properties of Cell Membranes. INSERM, Paris, pp $87-96$

37. Wetzel MG, Li J, Alvarez RA, Anderson RE, O’Brien PJ 1991 Metabolism of linolenic acid and docosahexaenoic acid in rat retinas and rod outer segments. Exp Eye Res 53:437-446

38. Anderson GJ, Connor WE, Corliss JD 1990 Docosahexaenoic acid is the preferred dietary $\omega 3$ fatty acid for the development of the brain and retina. Pediatr Res 27:81-87

39. Kohn G, Sawatzki G, Van Biervliet JP, Rosseneu M 1994 Diet and the essential fatty acid status of term infants. Acta Paediatr Suppl 402:69-74

40. Organisciak DT, Darrow RM, Jiang YL, Blanks JC 1996 Retinal light damage in rats with altered levels of rod outer segment docosahexaenoate. Invest Opthalmol Vis Sci 37:2243-2257

41. Su HM, Keswick LA, Brenna JR 1996 Increasing dietary linoleic acid in young rats increases and then decreases docosahexaenoic acid in retina but not in brain. Lipids 31:1289-1298

42. Robinson BS, Johnson DW, Poulos A 1990 Metabolism of hexacosatetraenoic acid (C26:4,n-6) in immature rat brain. Biochem J 267:561-564

43. Sharp P, Johnson D, Poulos A 1991 Molecular species of phosphatidylcholine containing very-long-chain fatty acids in human brain: enrichment in X-linked adrenoleukodystrophy brain and diseases of peroxisome biogenesis brain. J Neurochem 56:30-37

44. Huang JC, Voaden MJ, Marshall J 1990 Survival of structure and function in postmortem rat and human retinas: rhodopsin regeneration, cGMP, and the ERG. Curr Eye Res 9:151-162

45. Hong K, Hubbell WL 1973 Lipid requirements for rhodopsin regenerability. Biochemistry $12: 4517-4523$ 